\title{
APUNTES CRÍTICOS SOBRE EL CONCEPTO DE HEGEMONÍA EN DUSSEL Y LACLAU
}

Critical notes on the concept of hegemony in Dussel and Laclau

\author{
RODRIGO CASTRO ORELLANA \\ Universidad Complutense de Madrid (España) \\ rodrigocastro@filos.ucm.es
}

Resumen

El artículo estudia los aspectos fundamentales de la crítica de Dussel al modelo formal de hegemonía desarrollado por Laclau. En este contexto, se presenta la propuesta de una hegemonía popular ligada a la centralidad de la reproducción de la vida como criterio normativo de la política y se denuncia el decisionismo abstracto de la teoría populista laclauniana. Pero también en este texto se ofrece, siguiendo la lectura de Castro-Gómez, una crítica de las tesis de Dussel desde un punto de vista postfundacionalista, lo que supone cuestionar la idea misma de un universal incondicionado. Finalmente, concluimos exponiendo una crítica a algunas de las coordenadas teóricas compartidas por ambos autores, identificando las limitaciones del concepto mismo de hegemonía.

Palabras clave: Hegemonía; populismo; política; neoliberalismo.

\section{Abstract}

This article studies the fundamental aspects of Dussel's critique of the formal model of hegemony developed by Laclau. In this context, a concept of popular hegemony tied to the centrality of the reproduction of life as a normative criterion in politics is proposed, as well as an argument against the abstract decisionism of the populist theory of Laclau. The text also offers - as suggested by Castro-Gomez's reading - a critique of Dussel's ideas from a postfoundationalist perspective, which leads to questioning the very idea of an unconditional universal. Finally, we conclude by positing a critique of some of the theoretical viewpoints shared by both authors, identifying the limitations of the very concept of hegemony.

Palabras clave: Hegemony; populism; politics; neoliberalism.

Resulta significativo que Enrique Dussel y Ernesto Laclau -dos de los pensadores latinoamericanos más importantes de las últimas décadas- compartan un mismo contexto biográfico. Se trata del fenómeno político del peronismo en Argentina. Laclau inició su actividad militante en diversas agrupaciones políticas después del golpe de Estado que derrocó a Perón en 1955. Dussel, por su parte, padeció la persecución ideológica y sufrió un atentado en los turbulentos años 1972 y 1973, época del regreso de Perón del exilio.

Es muy probable que estas circunstancias expliquen el significado decisivo que adquiere para Dussel y Laclau pensar el problema del "pueblo" e intentar aclarar teóricamente la lógica interna que determina la acción de los movimientos sociales. 
No por nada, diversos autores latinoamericanos recibieron el proyecto de Dussel de una Filosofía de la liberación como una expresión de los principios ideológicos característicos del relato populista (Cerutti, 1983; Castro-Gómez, 1996) ${ }^{1}$. Una forma de discurso en la que precisamente se centra el análisis de Laclau y que constituye el aspecto fundamental de toda su ontología política.

En ambos casos, esta reflexión respecto del "pueblo" viene de la mano de un reconocimiento del papel que las instituciones representativas tendrían a la hora de la disputa por la hegemonía. Dicha función, según Dussel, solamente puede ponerse en práctica mediante una "refundación del Estado" que incluya las realidades subalternas excluidas por el paradigma moderno y que se oriente a la satisfacción de las necesidades vitales de los seres humanos. Esta dimensión constructiva de la institución también está presente en la obra de Laclau, pero se encuentra referida a una producción discursiva que no persigue ajustar la acción política a la necesidad material, sino más bien convertirla en un mecanismo para la creación de una identidad colectiva. De tal manera que, si bien Dussel y Laclau pueden estar de acuerdo con el valor de las instituciones políticas y en que estas se construyen hegemónicamente, difieren en cuanto a la forma en que se realiza dicho proceso.

Para Laclau, la hegemonía es un tipo de relación política (Laclau, Mouffe, 1987, p. 183) que asumiendo la ambigüedad y contingencia de toda esencia de lo social (p. 239), inviste provisoriamente una parcialidad como la plenitud ausente. Esto se consigue mediante la articulación de un conjunto heterogéneo de demandas que configuran un "bloque histórico", el que puede llegar a tener una identidad como consecuencia de la existencia de fuerzas antagónicas. Por el contrario, desde el punto de vista de Dussel, hay una única hegemonía legítima: aquella que tiene por objetivo responder a la materialidad de la vida y donde las voluntades se articulan en función de un consenso intersubjetivo que opera en el fondo último de todos los antagonismos y las prácticas divisorias de la sociedad.

Es decir, nos encontramos frente a dos modelos de hegemonía: uno formal y otro material. En el primero, la política se define como una disputa en el orden de los significantes que cristaliza en una identidad colectiva. En el segundo, toda acción política se somete al imperativo de dar respuesta a las necesidades de los cuerpos humanos, esto es: a su pobreza, su precariedad y sus carencias.

A continuación me detendré, en primer lugar, en una presentación general de los aspectos fundamentales de la crítica de Dussel al modelo formal de hegemonía. Después indicaré algunos de los supuestos filosóficos principales que dotan de sentido a la propuesta de Dussel, para - en un tercer momento- someterla a una evaluación crítica desde la perspectiva postfundacionalista de Laclau y de acuerdo con la lectura que ofrece Santiago Castro-Gómez. Finalmente, concluiré apuntando

\footnotetext{
${ }^{1}$ Hemos realizado un estudio crítico de dicho proyecto en un artículo titulado: "Liberation in Latin America" (Castro Orellana, 2016). Una versión más amplia de la misma cuestión puede encontrarse en: "Liberación" (Castro Orellana, 2017a).
}

124 | ALPHA No 48 (2019) PÁGS. 123-137. ISSN 0716-4254 
algunas coordenadas teóricas compartidas por los dos pensadores argentinos que, según nuestra opinión, limitan seriamente sus planteamientos.

\section{UNA HEGEMONÍA SIN ROSTRO}

En la crítica de Dussel a la teoría respecto del populismo de Laclau, subyace un debate decisivo en torno al marxismo. Como es sabido, la genealogía del concepto de hegemonía que construyeron Laclau y Mouffe demostró cómo la tradición marxista incurre en un reduccionismo de clase y en una concepción economicista de la historia que le han impedido pensar la contingencia y comprender a los sujetos como voluntades políticas complejas. En relación con esto último, Gramsci habría supuesto un instante clave determinante, porque instaló la necesidad de que la clase obrera transformase "su propia identidad articulando (...) una pluralidad de luchas y reivindicaciones democráticas" (Laclau, Mouffe, 1987, p.105).

Sin embargo, el análisis gramsciano no consigue superar una ambigüedad básica que lo conduce a reconocer al mismo tiempo la tarea histórico-contingente de producción de la hegemonía y el carácter necesario que le estaría asignado a la clase obrera como potencia articuladora. De este modo, según el planteamiento de Hegemonía y Estrategia Socialista, se interrumpiría el trabajo deconstructivo de la hegemonía (p. 104) iniciado por el autor italiano, al reintroducir un núcleo esencialista que establece la centralidad de una clase social en la lucha política. Para Laclau y Mouffe, esto no solo supone repetir el determinismo que convierte a la economía en última instancia y que ha lastrado la teorización marxista, sino que implica, además, excluir el espacio económico de los procesos de construcción hegemónica.

Dussel comparte en líneas generales la lectura que, en este contexto, Laclau y Mouffe realizan de Luxemburg, Kautsky o Plejanov (Dussel, 2001, p. 191-192). Está en condiciones de aceptar, por tanto, que en la tradición marxista "la lógica de la necesidad" ha negado e imposibilitado una reflexión radical acerca de "la lógica de la contingencia". Pero no está dispuesto a reconocer que este dogmatismo contra el que luchan Laclau y Mouffe sea un principio operativo que exista más allá del marxismo estándar, es decir, que tenga validez dentro de la obra del propio Marx (189-190). Habría que diferenciar el nivel económico y el nivel estratégico-político en la argumentación del autor alemán, aunque se trate en último término de aspectos complementarios.

En ese sentido, según Dussel, resulta indiscutible la existencia de determinaciones sociales que proceden del orden económico pero también la concurrencia de una lógica propiamente política. La clase obrera -por ejemploconstituiría un momento económico que, no obstante, se desarrolla como un "actor político" (Dussel, 2001, p. 190). Esto significaría que la hegemonía no puede concebirse como una pura articulación estratégica, ya que el nivel económico introduce un contenido objetivo material que consistiría en la reproducción de la vida. Desde este punto de vista, el ejercicio deconstructivo laclauniano de la hegemonía representaría una 


\section{Rodrigo Castro Orellana}

"reducción formalista política" que vacía "el horizonte cuasiautónomo de lo político con respecto a lo material, a la vida humana, a lo económico" (p. 191).

En cambio, dice Dussel, para Marx "el momento de determinación en última instancia de la historia es la producción y reproducción de la vida inmediata" (Dussel, 2001, p. 184). Por tanto, el fundamento no estaría en la estructura económica. Esta representaría más bien una mediación de la relación trabajo-naturaleza cuyo contenido último reside en la vida humana misma. La "voluntad de vivir" emerge, entonces, como el marco mínimo que debe sostener cualquier proyecto hegemónico, es decir, que determina tanto el ámbito de lo político como de lo económico.

Todo esto es lo que estaría en juego en la irrupción del problema de las "masas populares" dentro del pensamiento de Marx, un asunto que Laclau omite en su cuestionamiento del dogmatismo marxista. Ciertamente, Marx no utiliza nunca el término "pueblo" en el análisis abstracto de la estructura dialéctica del capital, pero sí lo haría en los análisis propiamente históricos (Dussel, 2001, p. 186). Por ejemplo: cuando se refiere a la prehistoria del capital, al momento en que "todavía no existe la clase obrera (porque no hay trabajo vivo como capital), como un período de expropiación terrible y dificultosa de las masas populares" (p. 187).

Marx recurriría a la palabra "pueblo" para nombrar el interregno que se produce entre la disolución de un sistema económico y el tránsito hacia uno nuevo, donde la categoría "clase" no se puede todavía utilizar porque no se ha alcanzado aún la formación de una totalidad que determine a las masas populares como obreros asalariados (Dussel, 2001, p. 188). Esto quiere decir que mientras "las clases" dependen estrictamente de un modo de producción, el "pueblo" es independiente del modelo esclavista, la formación feudal del siervo o el trabajo asalariado. El "pueblo" o "los pobres", entonces, constituye el verdadero elemento de continuidad histórica en el planteamiento de Marx. Habría una materialidad de la vida que se presenta históricamente como precariedad y sujeción, la cual traza sin fuerza inexorable alguna el conjunto de las regularidades y las tendencias que afectan al espacio sociopolítico.

Así pues, cuando Laclau critica el carácter necesario que la tradición marxista le otorga a la clase obrera como sujeto de la articulación hegemónica, desatiende la especificidad de la posición de Marx que estaría -según Dussel- muy lejos de cualquier tipo de esencialismo. De esta forma, Laclau cree haber ajustado cuentas con el materialismo histórico, toda vez que ha procedido a una labor de deconstrucción radical de aquellos principios que él considera que le son constitutivos. Sin embargo, su aparato crítico realmente no consigue medirse con las tesis originales de Marx, lo que explica ciertos problemas que afectan a su concepto de hegemonía.

En efecto, la incapacidad de Laclau para distinguir el nivel de los modos de producción económica (con sus leyes inmanentes), del nivel que correspondería a la objetiva "voluntad de vivir" de los sujetos, lo conduce a perder de vista el rol que la materialidad cumpliría en las luchas democráticas (Dussel, 2001, p. 196). Habría un vaciamiento formalista de la acción estratégico-política en la teoría de la hegemonía 
laclauniana (p. 183) que evidencia la existencia de un criterio antieconomicista. No es extraño, por tanto, que su propuesta no consiga ofrecer un modelo preciso para rearticular lo económico con lo político y que su prioridad no resida en la subversión del capitalismo, sino en la afirmación de la democracia radical y en el reconocimiento de las instituciones liberales.

Para Dussel, todas estas dificultades de la perspectiva de Laclau serían consecuencia de su opción por una ontología del discurso. De acuerdo con dicho enfoque, un objeto solamente podría constituirse como tal dentro de una estructura discursiva que lo dote de significación. Este sistema discursivo sería una red de relaciones de diferencias, en que cada uno de los elementos constitutivos se definiría a partir de las relaciones que establece con otro y donde no existiría ningún fundamento a priori, ni tampoco principios incondicionados que introduzcan sentidos necesarios. En el plano político, esto se traduciría en que un acontecimiento solo podría adquirir un sentido dentro de la lucha por la hegemonía.

Pero esta hegemonía descrita en estos términos carecería de rostro. Por eso Dussel rechaza que el orden estratégico-discursivo sea el último marco de determinación de la validez de la acción y defiende la existencia de al menos dos reglas previas que no pueden ser desconocidas (Dussel, 2001, p. 199). Se trata, en primer lugar, de la vida humana como criterio normativo de la hegemonía y, en segundo término, de la aceptación del antagonista político como alguien con el que compartimos ciertos principios del juego democrático (sin los cuales, en vez de hegemonía lo que tendríamos sería dominación). Laclau se equivoca, entonces, cuando analiza -por ejemplo- el célebre lema "Pan, Paz, Tierra" de la Revolución Rusa como un significante vacío que permitiría articular una heterogeneidad de luchas a partir de la ausencia formal de una plenitud (Laclau, 2005, p. 127). Cuando un movimiento reclama: "Pan, Paz, Tierra" estaría apelando en realidad a una exigencia básica más elemental: “¡No debes matarme!”. Por esta razón, lo que enlaza las diferentes luchas constituye un contenido positivo concreto: el deseo de todo ser humano de reproducir la vida (Dussel, 2001, p. 203).

Esto no significa - de acuerdo con el criterio de Dussel-negar la importancia de la lucha política por la hegemonía y el contexto contingente en que esta se desenvuelve. El punto decisivo residiría en que esa dimensión beligerante de la acción política no puede excluir los marcos materiales que condicionan su ejercicio (p. 208). En ese sentido, la "demanda democrática" no debería ser reconocida como la unidad mínima en el análisis de la lógica populista, como lo sostiene Laclau (2005, p. 99). Más allá de las peticiones o reclamos contrapuestos que los individuos pueden dirigir a una instancia institucional o gubernamental, se encuentran un conjunto de necesidades inmediatas y universales como son el comer, beber, vestirse, disponer de una vivienda, etcétera (Dussel, 2001, p. 207).

No asumir este marco normativo fundamental, referido a los criterios de vida y muerte, conduciría a la teoría de Laclau a una zona de opacidad que le impide 


\section{Rodrigo Castro Orellana}

identificar algún principio que haga posible diferenciar una hegemonía autoritaria de una hegemonía "popular" (p. 199) o, un populismo de derecha de un populismo de izquierda. El planteamiento de Laclau, paradójicamente, parece resultar más exitoso en su tarea de deconstrucción del dogmatismo de izquierda, arrastrando con ello los contenidos éticos que justifican una voluntad emancipadora, que en una posible labor de deconstrucción de la razón neoliberal (Dussel, 2001, p. 205).

$\mathrm{El}$ antifundacionalismo de Laclau y su fetichización del formalismo estratégico, no solamente le impedirían comprender la articulación entre lo político y lo económico en la lucha hegemónica, sino que también nos dejaría desprovistos de razones y motivaciones para legitimar la acción de los movimientos sociales contra la hegemonía neoliberal. Dussel cree, entonces, que ha llegado el momento de construir alternativas efectivas y que estas pasan principalmente por asumir la identidad del "pueblo" como un hecho y no como el horizonte de una producción retórica.

\section{UNA HEGEMONÍA POPULAR}

La propuesta de Dussel tiene como premisa que la verdadera política es aquella que garantiza "que todos los miembros de una sociedad puedan al menos vivir, esto es, tener cubiertas sus necesidades básicas" (Castro-Gómez, 2015 p. 338). El cuerpo, entonces, emerge como un a priori de la lucha hegemónica y como el elemento que permite conectar la acción política con el orden económico.

Sin embargo, este planteamiento de Dussel no resulta tan evidente como en principio podría parecernos. Cuando nuestro autor contrapone la "voluntad de poder" característica del concepto formalista de hegemonía, a la "voluntad de vivir" como criterio último del espacio político (Dussel, 2001, p. 183), no está identificando algo así como un sustrato biopolítico en el sentido foucaultiano (Castro-Gómez, 2015, p. 339). La materialidad que aquí Dussel pretende establecer no se corresponde con la "colonización" del bios por parte de una serie compleja de dispositivos de gobierno o de tecnologías de poder. No se trata de una acción política que modela el horizonte vital de los sujetos, sino todo lo contrario: de que cualquier praxis política está determinada desde un principio por la expansión material de la vida.

Por otro lado, tampoco sería correcto, en los términos de Dussel, calificar a esta "voluntad de vivir" como una manifestación primigenia de la condición humana, es decir, como la expresión de un estado genético individual, prerreflexivo o prelingüístico. La "voluntad de vivir" equivaldría más bien a una experiencia común (Castro-Gómez, 2015, p. 339). Se corresponde con aquello que Heidegger describió como una de las estructuras fundamentales del Ser-ahí (Dasein): el Ser-con-Otros. Dicho de otro modo: la materialidad vital que reivindica Dussel se refiere al hecho de que todo sujeto requiere de una relación con los otros para asegurar y desarrollar su existencia. La vida individual estaría absolutamente ligada al destino de la comunidad, a su capacidad de subsistir y perfeccionarse. 
En su obra Política de la liberación recurre a la distinción entre potestas y potentia para explicar esta dimensión intersubjetiva de la "voluntad de vivir". Se trataría de considerar la diferencia ontológica en el campo político, porque la potentia constituye el poder de la comunidad política misma y la potestas el poder delegado mediante la representación (Dussel, 2009, p. 60-61). La potentia, entonces, encarnaría el momento básico o constituyente antes de cualquier acción política o de cualquier articulación institucional. Sin embargo, dicho momento prepolítico -según Dusselno puede ser concebido como un estado de naturaleza en que prima la lucha irreflexiva y la dispersión caótica entre los individuos. Por el contrario, la potentia correspondería a una realidad inmediatamente consensual, es decir, equivale a una "fuerza racional e intersubjetiva" (Castro-Gómez, 2015, p. 343).

Pero ¿cómo es posible que emerja una "razón universal" en una instancia prepolítica, antes de cualquier orden institucional o cultural? La respuesta de Dussel apunta a que la pluralidad de voluntades del momento constituyente posee un elemento en común que es el querer vivir. El hombre, en tanto que ser pensante, se encuentra orientado éticamente hacia el consenso, se dirige hacia una construcción de sí mismo como individuo que resulta inseparable de la vida colectiva.

No obstante, sería un error interpretar esta relación entre potentia y potestas como una secuencia temporal. Lo que Dussel pretende dejar muy claro es que la potentia involucra "un momento fundamental que permanece siempre en acto debajo de las instituciones y acciones (debajo de la potestas)" (Dussel, 2006, p. 31). Todo el ámbito de la potestas, por tanto, remitiría a la voluntad popular originaria. La praxis hegemónica o la política representativa estarían sujetas, de un extremo al otro, al consenso intersubjetivo que se encontraría dado desde un principio.

Esto no quiere decir que no existan conflictos, contradicciones, ni un juego de intereses y tácticas en la lucha por el poder político. La clave del problema estaría - para Dussel- en que detrás de todo antagonismo o de cualquier articulación estratégica de la racionalidad, existiría un mundo común de carácter normativo que debe ser reconocido por todos los que participan en cualquier deliberación política (Castro-Gómez, 2015, p. 349).

Las consecuencias de este planteamiento, como se comprenderá, son múltiples. En primer lugar, pone de manifiesto que si Laclau parte de una ontología de la incompletud que justifica la capacidad compensatoria y el poder persuasivo de los significantes vacíos, Dussel opera desde una ontología de la plenitud como un imperativo ético que determina la legitimidad de los significantes y que rechaza el decisionismo político abstracto. Así pues, si bien ambos autores consideran que no es posible prescindir del concepto de universalidad, uno la entiende como una producción política (un significante que se modela en el ámbito de la potestas) y otro la define como una dimensión esencialmente ética.

Esta universalidad ética es el verdadero nombre de esa materialidad vital que Dussel pretende situar como principio normativo de la política y de la economía. 


\section{Rodrigo Castro Orellana}

Desde este supuesto, el problema de la hegemonía estaría mal formulado si se considera que una estrategia política puede realizarse plenamente en el momento formal de su ejercicio, sin contenido alguno (Dussel, 2001, p. 215). Esta sería una "hegemonía por la hegemonía misma", cuando de lo que se trata es de constituir una "hegemonía a favor de los oprimidos" (Dussel, 2009, p. 127). El populismo, entonces, no puede agotar su sentido en la tarea necesaria pero insuficiente de la "deconstrucción" de un "bloque de poder" o en las maniobras propias de una "máquina de guerra" que aspira a la hegemonía. Dussel tiene la convicción de que el populismo debe interrogarse por los criterios de uso de la hegemonía (¿para qué?, ¿en nombre de qué?, etcétera) o, para decirlo con mayor propiedad, tiene que problematizar su capacidad de cumplir con los intereses o las interpelaciones populares (Dussel, 2001, p. 216).

Todo esto se traduce en la inevitable labor de reconstrucción de la categoría "pueblo". Algo que Dussel identifica con el proyecto filosófico en que ha estado embarcado durante las últimas cuatro décadas. La filosofía de la liberación, en tal sentido, enseñaría un camino para obtener un nuevo concepto de "pueblo" que pasa por atender a su "localización latinoamericana" (p. 216) y asumir la diferencia colonial . Desde esta perspectiva, la experiencia del colonialismo nos mostraría la existencia de una "potencialidad no incluida" (Dussel, 2001, p. 387) en la modernidad occidental que se refiere a saberes y prácticas que han sido en algún momento excluidas.

Más allá del "orden-mundial" y de la supuesta "realidad sistemática" y universal de la modernidad existirían espacios culturales que han sido rechazados o negados, pero que realmente son ancestrales y han sobrevivido a lo largo de los siglos al aparato de subalternización eurocéntrico (p. 405). Estos órdenes culturales contendrían, según Dussel, un potencial de humanidad decisivo para la construcción de una civilización futura que supere radicalmente a la modernidad y al capitalismo.

Por este motivo, la idea de transmodernidad no supone solo una perspectiva crítica de los valores occidentales, sino también una propuesta política de liberación de los pueblos que nace de una reivindicación de las identidades culturales despreciadas o ignoradas. Aquello que la modernidad calificó como "insignificante", "sin sentido", "bárbaro", "salvaje", "subdesarrollado" o "tercermundista" se transformaría ahora en la fuente principal de saberes y prácticas decisivas para la construcción de un nuevo paradigma civilizatorio que asegure la subsistencia del hombre en el planeta (Dussel, 2001, pp. 406-407). Se trataría del retorno del inconsciente histórico excluido (p. 407) que arremete contra la pretensión totalizadora de la modernidad, como una fuerza que contiene una heterogeneidad reprimida y una identidad común.

\footnotetext{
${ }^{2}$ El concepto de diferencia colonial ha sido propuesto por Walter Mignolo en el contexto del Grupo Modernidad/Colonialidad. He establecido una discusión crítica con esta y otras nociones desarrolladas por Mignolo en: "Diferencia colonial y pensamiento fronterizo. El privilegio de Walter Mignolo" (Castro Orellana, 2015a).
}

130 | ALPHA No 48 (2019) PÁGS. 123-137. ISSN 0716-4254 
En suma, la categoría "pueblo" nos exigiría pensar desde las nociones de "alteridad" y "exterioridad" aquello que Lévinas definió como el Otro; el rostro de la víctima, del pobre o del desamparado que me interpelan diciendo "No matarás" (Lévinas, 1995, p. 22) ${ }^{3}$. Por este motivo, Dussel considera adecuado introducir una distinción final entre los términos "popular" y "populista". Lo "popular" se correspondería con el reclamo que surge de la materialidad del oprimido, de su vulnerabilidad y de su extrema disposición para la muerte, mientras que lo "populista" tendría que ver con la instrumentalización que se realiza de las interpelaciones del pueblo para conquistar una mayoría que realmente no logra interrumpir la historia de la dominación (Dussel, 2001, p. 219). La alternativa, por tanto, no podría ser otra que colocar a la filosofía al servicio de la lucha antihegemónica de los grupos populares.

\section{LOS LÍMITES DE LA HEGEMONÍA}

Como se advertirá, las posiciones teóricas de Dussel y Laclau reproducen una antigua querella filosófica. Por una parte, tendríamos un pensamiento político fundacionalista que defiende la necesaria existencia de criterios normativos a priori y, por otro lado, nos encontraríamos con una perspectiva postfundacional que establece el carácter puramente contingente de la política. Hasta aquí hemos visto los aspectos principales de la crítica de Dussel a este segundo concepto de hegemonía defendido por Laclau. Nos corresponde ahora identificar la réplica que un punto de vista postesencialista podría dar a estos cuestionamientos.

Para esta tarea nos guiaremos por algunas de las observaciones que CastroGómez ha hecho en relación con este problema.

En este contexto, lo primero que cabría señalar es que la materialidad que Dussel presenta como un marco normativo último, esto es: las necesidades básicas de los seres humanos y el hecho mismo de la pobreza, ocultarían una precariedad mucho más radical. Esta dimensión se referiría, de acuerdo con el enfoque de Laclau (muy influenciado por Lacan), a una condición fundamental de la vida de todo ser humano: su incompletud. Antes de cualquier precariedad relacionada con la subsistencia material del sujeto, este experimentaría una vulnerabilidad fundamental que afectaría a todo su ser.

En La Razón Populista, Laclau explica este punto recordando la noción freudiana de la madre primordial y la separación originaria entre la plenitud inalcanzable y aquello que es lo representable (Laclau, 2005, p. 144). El hecho de que exista algo de esa madre primordial que no puede ingresar en el orden de la representación, abre una brecha en el nivel de los significantes (p. 145). Lacan radicaliza este planteamiento, afirmando que lo que aquí estaría en juego no es una imposibilidad

\footnotetext{
${ }^{3}$ Para un estudio de la relación entre el pensamiento de Dussel y Lévinas, véase el trabajo: Geopolítica de la alteridad. Lévinas y la filosofia de la liberación de E. Dussel (García, 2014).
} 


\section{Rodrigo Castro Orellana}

del pensamiento, sino un vacío del ser. La pérdida del goce que une al sujeto con la totalidad materna, agota a partir de ese momento cualquier ámbito de su experiencia. Esto significa que la aspiración a la plenitud no desaparece, sino que es "transferida a objetos parciales que son los objetos de las pulsiones" (Laclau, 2005, p. 147), un aspecto clave para entender el proceso de investidura de una particularidad como significante vacío dentro de la praxis hegemónica.

Para Laclau la condición humana está determinada por este desgarro constitutivo que nos sitúa en la completa ausencia de estructuras normativas. Dicha "falta" no sería otra cosa que el nombre mismo de la libertad. Por eso resulta tan significativo el uso que Dussel hace del concepto "liberación", ya que implica reducir la cuestión ontológica de la libertad a una condición óntica que depende de la satisfacción o no de las necesidades materiales (Castro-Gómez, 2015, p. 351). Las nociones de libertad y liberación deberían diferenciarse, desde el punto de vista de Laclau, porque la primera constituye la verdadera condición de posibilidad de cualquier forma de lucha que pretenda mejorar las condiciones de vida de los hombres.

Por otro lado, la ausencia de plenitud cuestiona la tesis dusseliana de una "voluntad de vivir" como estructura sólida que permite normativizar la acción política. Según Laclau, jamás una voluntad podría considerarse como una realidad plena porque siempre estaría sobredeterminada, es decir, sumida dentro de una red contingente de relaciones antagónicas de fuerza (Castro-Gómez, 2015, p. 350). La pretensión de Dussel respecto de una eventual fundamentación ética de la política podría ser interpretada, entonces, como una operación de despolitización que niega los antagonismos sociales y el complejo juego de relaciones de poder en que no tiene cabida un universal incondicionado.

Ahora bien, estas observaciones de Castro-Gómez nos permiten avanzar en la dirección de algunas conclusiones acerca del problema de fondo de la hipótesis hegemónica. Entendemos, en primer lugar, que no es lo mismo apelar a la materialidad de la vida que suponer que dicha materialidad equivale a la voluntad de un "pueblo oprimido". Con este desplazamiento, según nuestro punto de vista, Dussel abandona cualquier posibilidad de un materialismo coherente y restaura el idealismo metafísico de una sustancia identitaria transhistórica. Dicho esencialismo se pone de manifiesto con mucha claridad en la connotación que él mismo le ha otorgado a conceptos como "liberación" o "transmodernidad".

La idea de una "filosofia de la liberación", por ejemplo, pretende describir una forma de pensamiento auténtico que emergería del sujeto histórico oprimido de Latinoamérica. De un modo equivalente, la noción de "transmodernidad" apunta a un más allá de la modernidad que se correspondería con las cosmovisiones periféricas que esta ha intentado suprimir. En ambos casos, se trata de una perspectiva que afirma estar en condiciones de hablar en nombre de los oprimidos o los excluidos.

Dussel se identificaría, por tanto, con la función representativa del intelectual a partir de una comprensión de la representación como actividad de delegación en que el 
saber experto cumple el papel de portavoz de los más desfavorecidos. Este modelo, como es sabido, ha sido seriamente interpelado por las teorías críticas contemporáneas y las posiciones deconstructivas que invierten esta lógica de la representación para establecer la primacía del discurso sobre cualquier producción de identidad. Este es el caso de Laclau, para quien la función del representante no es actuar en nombre e interés de un conjunto de sujetos, sino construir la identidad política colectiva de los representados mediante la creación y la disputa de los significantes.

Hablar en nombre de los oprimidos, como lo expresó Gayatri Spivak, es un acto de violencia que niega la diferencia y multiplicidad del subalterno y los condicionamientos institucionales que impiden su representación (Spivak, 2011). Implica una operación de homogeneización de los sujetos en donde se recorta su heterogeneidad a favor de un modo de subjetividad privilegiado. Esto ocurre en el planteamiento de Dussel, especialmente cuando se sugiere que todo el ámbito de la potentia debe ser concebido como una "voluntad de vivir", cuya fuerza se disolvería en su desplazamiento al orden institucional. ¿No existe una subalternidad que escape al sustrato de la materialidad y que no resulte recuperable en la lógica de la potestas?

Un problema similar podemos advertir en la propuesta de Laclau, pese a su crítica del paradigma clásico de la representación. Para observar esto último hay que detenerse en la noción de subjetividad que involucra la tesis formulada en La Razón Populista acerca de que las demandas sociales constituyen la unidad básica desde donde surge la construcción populista. Compartimos en este punto lo señalado por Castro-Gómez, en cuanto a que detrás de esta apuesta por un sistema articulatorio de exigencias insatisfechas se encontraría una operación de igualación de los sujetos que reduce su acción a la de meros litigantes que dependen de lo que piden o reciben del Estado (Castro-Gómez, 2015, pp. 370-371). Sin embargo, en nuestra opinión, esto evidencia un problema que interpela radicalmente el uso que podemos realizar del pensamiento de Laclau, ya que existe una identificación de fondo entre la subjetividad populista y el estilo psíquico del sujeto neoliberal que establece un vínculo estrictamente clientelar con las instituciones.

En contraposición a estas subjetividades reactivas que servirían de base para la configuración de un "pueblo", y más allá de esas subjetividades enmarcadas en la materialidad vital que -según Dussel- encarnan la verdad misma del subalterno, se hallarían otras subjetividades que despliegan luchas micropolíticas que no aspiran a una articulación ni buscan su universalización. Existiría una "negatividad subalterna no equivalencial" que evidencia las limitaciones de la hipótesis general de la hegemonía que comparten nuestros dos autores y algunos de sus críticos como Castro-Gómez. Es decir, habría una oposición multiforme a los poderes oligárquicos que no resulta recuperable en el proceso de conquista de una voluntad mayoritaria ni en la toma por asalto de las instituciones.

En esta perspectiva se inscribe el libro de Richard J.F Day: Gramsci is dead. En la misma medida en que Laclau y Mouffe realizaron una tarea de deconstrucción 
del concepto de hegemonía inspirada en los nuevos movimientos sociales de fines de los años ochenta del siglo XX, Day considera que las formas de activismo que responden en la actualidad a la razón neoliberal deben ser tenidas en cuenta a la hora de pensar los límites de la lógica de la hegemonía. En ese sentido, desde ya hace algunos años existirían diversas tácticas nohegemónicas orientadas a subvertir las instituciones y poner en dificultad algunas de las líneas de fuerza del modelo político y social dominante. Se trataría de prácticas radicales que apuestan en general por el anarquismo como estilo de vida, entre ellas estarían: la reactualización de técnicas situacionistas que critican la estructura ideológica de la publicidad (por ejemplo: el Bilboard Liberation Front) o la sociedad del control y la vigilancia (por ejemplo: Surveillance Camera Players), nuevas formas de desobediencia civil que pretenden intervenir en las calles (por ejemplo: los grupos black bloc), acciones de ataque a las infraestructuras informáticas (por ejemplo: el hacktivismo), etcétera (Day, 2005). En todas estos movimientos no hay ningún deseo de articulación universal ni ningún proyecto de construcción de una mayoría para obtener la reforma de las instituciones. Son manifestaciones anárquicas que el discurso de la hegemonía descalifica en términos similares a como la ortodoxia marxista despreció en su oportunidad la realidad del lumpenproletariat. Creo que esto es un error porque el anarquismo nos enseña algo: que la producción de cambios significativos en la sociedad no descansa exclusivamente en la lucha hegemónica, sino que debe incorporar también otros ámbitos en que se llevan a cabo revoluciones cotidianas en el orden de los valores y los modos de vida. Esto es lo que implica el concepto de poshegemonía que hemos propuesto en otros contextos: no una descalificación de la idea misma de una política de la hegemonía, sino la necesidad de complejizar el espacio de los antagonismos (Castro Orellana, 2015b, 2017b, 2018).

Todo lo anterior pone de manifiesto, además, un reduccionismo político que afecta en igual medida a Laclau y Dussel. En efecto, el enfoque teórico de la hegemonía populista no comprende que existen sentidos que se establecen más allá del orden del discurso y que involucran dispares modos de afectación de las relaciones de poder en los sujetos. No todo el problema político se reduce a la conquista de los aparatos del Estado, a la disputa de los nombres o los conceptos o al juego discursivo de construir al enemigo.

De un modo similar, la hegemonía popular propuesta por Dussel no logra distinguir con claridad los ámbitos propiamente institucionales y la realidad diversa y compleja de la sociedad. Esto deriva en una idea de la democracia como un acontecimiento que debe contener la redención radical del pueblo oprimido y que solamente puede materializarse en la estructura orgánico-institucional de la sociedad. Se rechaza, por tanto, una concepción de la democracia como un ámbito de antagonismos y disputas en torno a las formas de nombrar al pueblo o como una praxis independiente de los poderes institucionales. 
Se ha dicho en más de alguna oportunidad que los fenómenos políticos latinoamericanos del siglo XXI demostrarían la importancia de las instituciones representativas para disputar la hegemonía del neoliberalismo. De hecho, como hemos indicado al principio, esta es una idea que atraviesa decisivamente las propuestas de Dussel y Laclau. Sin embargo, también el caso de América Latina nos enseña otras cosas. Por ejemplo: las insuficiencias de este argumento organicista y la complejidad de los mecanismos de gobierno neoliberal a la hora de obtener el consentimiento de las masas. Solamente así puede explicarse que la voluntad mayoritaria en algunas sociedades pueda desplazarse sin dificultades de un apoyo a opciones populistas de izquierda, a un respaldo de proyectos políticos de centro o extrema derecha.

Aquí me parece que reside la gran aportación del análisis de Foucault respecto del neoliberalismo: constatar que este es una forma de gobierno que requiere de una específica tecnología del yo, es decir, de un proceso de subjetivación que organiza los cuerpos (Foucault, 2004). Los antagonismos y las posiciones dentro del tablero neoliberal no se reducen a la lucha por los significantes ni tampoco al incremento de un poder institucional. Todo esto resulta insuficiente si no se reconoce la existencia de otros antagonismos que deben intensificarse y que corresponden al modo en que los sujetos se relacionan consigo mismos, a los valores y prácticas con que estos se autoconstituyen. Ahí, en ese territorio desatendido por las teorías de Dussel, Laclau y los "conversos" al discurso de la hegemonía ${ }^{4}$, se lleva a cabo una invasión solapada y penetrante por parte de la racionalidad neoliberal de los deseos, los intereses y las ideas de los individuos.

Se trata de una colonización de la vida que busca instalar un poder indiviso y unívoco. Algo que no está tan alejado como pareciera de las aspiraciones que subyacen en la concepción hegemónica de la política. Es lo que podemos advertir en el sueño de Dussel de una potestas que se identifique completamente con la potentia, es decir, de un único poder que encarne radicalmente la materialidad sufriente. Así se establece la preponderancia de un determinante absoluto que garantizaría el consenso universal.

\footnotetext{
${ }^{4}$ El fenómeno político surgido en 2014 en España y que condujo al nacimiento de Podemos vino acompañado de una verdadera reactivación acelerada de las lecturas acerca de Gramsci y Laclau a propósito del problema de la hegemonía. Este interés teórico por los conceptos de hegemonía y populismo tenía un antecedente previo en la experiencia política latinoamericana de gobiernos de izquierda de la primera década del siglo XXI. En el contexto de lo que podríamos denominar fase caliente del discurso de la hegemonía, se desplegaron todo tipo de críticas hacia las posiciones políticas que intentaban todavía sostener el diagnóstico clásico del marxismo o hacia cierto tipo de análisis posestructuralistas (Deleuze, Foucault) porque serían incapaces de ofrecer alternativas. Los "conversos de la hegemonía" cerraron apresuradamente la puerta a cualquier nueva utilización de Marx y sentenciaron, por ejemplo a Foucault, como un autor anarquista que no ofrecía herramientas para la acción de los movimientos sociales. Ahora que hemos entrado en una fase fría del "efecto Podemos" y en una época de desarticulación de los gobiernos antineoliberales en América Latina, quizás sea el momento más oportuno para que evaluemos las razones histórico-filosóficas que explican estos fracasos y estos retrocesos de proyectos políticos centrados en la idea de hegemonía. Para una historia de la emergencia y de las tensiones internas de Podemos, véase: El lento aprendizaje de Podemos (Villacañas, 2017).
} 
Pero tal vez, como escribió Odo Marquard, más importante que el consenso sea la pluralización de la vida (Marquard, 2006, p. 138). Esta dimensión de la contingencia o de la ausencia de determinaciones absolutas es lo que precisamente reivindica la posición deconstructivista de Laclau. Sin embargo, el autor de La Razón Populista no consigue desprenderse por completo de la nostalgia que produce abandonar el sueño de un poder indiviso y unívoco. El problema de lo absoluto reaparece en su filosofía como un recurso decisivo para explicar la fuerza de los afectos en la articulación de los significantes políticos. En efecto, la eficacia en la construcción de un poder colectivo se encuentra completamente condicionada por su capacidad de compensar la ausencia de lo absoluto.

Ciertamente, el ser humano es un homo compensator (Marquard, 2012, p. 18), pero no necesariamente lo que compensa guarda relación con una falta constitutiva o una precariedad ontológica, en donde la búsqueda de lo absoluto cumple siempre un papel determinante. Las compensaciones pueden estar referidas a carencias físicas que perfilan nuestra experiencia como seres corpóreos, de un modo tal que los rendimientos sustitutivos no pueden permitirse una hipotética restauración de lo absoluto, sino que deben incorporar lo imperfecto, el azar y la contingencia.

En suma, lo que hace al hombre libre no es la ausencia de todo determinante, en el sentido en que lo concibe Laclau, ni tampoco la producción de un determinante sublime como pretende Dussel, sino "la sobreabundancia de determinantes" (Marquard, 2012, p. 77). En la pluralidad de la vida reside el horizonte compensatorio de la existencia humana y en la división de los poderes está la garantía de nuestra libertad.

\section{OBRAS CITADAS}

Castro-Gómez, Santiago (2015). Revoluciones sin sujeto. Slavoj Žižek y la crítica del historicismo posmoderno. Madrid: Akal.

_ (1996). Crítica de la razón latinoamericana. Barcelona: Puvill.

Castro Orellana, Rodrigo (2018). "Foucault y Laclau. Resistir sin un afuera", en: José Luis Villacañas Berlanga, Rodrigo Castro Orellana (Eds.), Foucault y la Historia de la Filosofía. Madrid: Dado Ediciones, 393-418.

(2017a). "Liberación”, en: Alberto Moreiras, José Luis Villacañas (Eds.), Conceptos fundamentales del pensamiento latinoamericano actual. Madrid: Biblioteca Nueva, 383-400.

— (2017b). "Crítica de la razón latinoamericana. Veinte años después", en: Adán Salinas (Ed.), Filosofía política y genealogías de la Colonialidad. Diálogos con Santiago Castro-Gómez. Viña del Mar: Cenaltes, 21-45.

(2016). "Liberation in Latin America", The Encyclopedia of Postcolonial Studies. Ray, Sangeeta, Henry Schwarz, José Luis Villacañas Berlanga, Alberto Moreiras and April Shemak (eds). Blackwell Publishing, pp. 958- 964. 
_ (2015a). "Diferencia colonial y pensamiento fronterizo. El privilegio de Walter Mignolo", en: Daniel Abraldes (Ed.), Ideas que cruzan el Atlántico: Utopía y modernidad latinoamericana. Madrid: Escolar y Mayo, 211-232.

_ (2015b). Poshegemonía. El final de un paradigma de la filosofía política en América Latina (Ed.). Madrid: Biblioteca Nueva.

Cerutti, Horacio (1983). Filosofía de la liberación latinoamericana. México: Fondo de Cultura Económica.

Day, Richard J. F. (2005). Gramsci is Dead: Anarchist Currents in the Newest Social Movements. Londres: Pluto Press.

Dussel, Enrique (2009). Política de la liberación, Vol. II, Arquitectónica. Madrid: Trotta.

— (2006). 20 tesis de política. México: Siglo XXI.

(2001). Hacia una filosofía política crítica. Bilbao: Desclée de Brouwer.

Foucault, Michel (2004). Naissance de la biopolitique. Cours au Collège de France. 1978-1979, Paris: Gallimard/Seuil.

García Ruiz, Pedro Enrique (2014). "Geopolítica de la alteridad. Lévinas y la filosofía de la liberación de E. Dussel”. Isegoría, № 51 (julio-diciembre): 777-792.

Laclau, Ernesto (2005). La razón populista. Buenos Aires, Fondo de Cultura Económica.

Laclau, Ernesto y Mouffe, Chantal (1987). Hegemonía y Estrategia Socialista. Hacia una radicalización de la democracia, Madrid, Siglo XXI.

Lévinas, Emmanuel (1995). Difficile liberté, Paris, Albin Michel.

Marquard, Odo (2012). Individuo y división de poderes. Estudios filosóficos. Madrid: Trotta. — (2006). Felicidad en la infelicidad. Reflexiones filosóficas. Buenos Aires: Katz.

Spivak, Gayatri (2011). ¿Puede hablar el subalterno? Buenos Aires: El cuenco de plata. Villacañas, José Luis (2017). El lento aprendizaje de Podemos. Madrid: Catarata. 